Supplementary Materials for

Library of Two-Dimensional Hybrid Lead Halide Perovskite Scintillator Crystals

Aozhen Xie ${ }^{1,2, *}$, Francesco Maddalena ${ }^{1,2, *}$, Marcin E. Witkowski ${ }^{3}$, Michal Makowski ${ }^{3}$, Benoit Mahler $^{4}$, Winicjusz Drozdowski ${ }^{3}$, Stuart Victor Springham ${ }^{5}$, Philippe Coquet ${ }^{1,2,6}$, Christophe Dujardin $^{4, \dagger}$, Muhammad Danang Birowosuto ${ }^{1,2, \dagger}$, and Cuong Dang ${ }^{1,2, \dagger}$

${ }^{1}$ School of Electrical and Electronic Engineering, Nanyang Technological University, 50 Nanyang Avenue, 639798, Singapore

${ }^{2}$ CINTRA UMI CNRS/NTU/THALES 3288, Research Techno Plaza, 50 Nanyang Drive, Border X Block, Level 6, 637553, Singapore

${ }^{3}$ Institute of Physics, Faculty of Physics, Astronomy, and Informatics, Nicolaus Copernicus University in Torun, ul. Grudziadzka 5, 87-100 Torun, Poland

${ }^{4}$ Universitè de Lyon, Universitè Claude Bernard, Lyon 1, CNRS, Institut Lumière Matière UMR5306, Villeurbanne F-69622, France

${ }^{5}$ Natural Sciences and Science Education, National Institute of Education, 1 Nanyang Walk, 637616, Singapore

${ }^{6}$ Institute of Electronics, Microelectronics and Nanotechnologies (IEMN), CNRS UMR 8520University of Lille, 59650 Villeneuve d'Ascq Cedex, France

*These authors contributed equally to this work.

†Corresponding Authors. Email: $\quad$ mbirowosuto@ntu.edu.sg; hcdang@ntu.edu.sg; christophe.dujardin@univ-lyon1.fr 


\section{Sheet lists}

Table S1 Perovskite compounds, molecular formulas, volumes, mass densities, and atomic effective numbers.

Figure S1 Attenuation lengths of eleven perovskites.

Figure S2 XRD pattern for some of the investigated perovskites and the respective theoretical lines.

Figure S3 Schematic representation of the structure of the 2D-perovskites.

Figure S4 Theoretical interlayer distance of the 2D perovskites vs. measured diffraction angle.

Figure S5 Centimeter-sized 2D-perovskite crystals

Figure S6 PLE and PL of three of our 2D perovskites.

Figure S7 Photoluminescence (PL), X-ray luminescence (XL) of bulk crystal and nanocrystalline films of $(\mathrm{BA})_{2} \mathrm{PbBr}_{4}$ and $(\mathrm{BA})_{2} \mathrm{PbI}_{4}$.

Figure S8 Time-resolved PL of 2D-perovskite crystals and thin films.

Figure S9 Temperature-dependent $\mathrm{XL}$ of $(\mathrm{API}) \mathrm{PbBr}_{4}, \quad(\mathrm{AEIU}) \mathrm{PbBr}_{4}, \quad(\mathrm{PEA})_{2} \mathrm{PbBr}_{4}$, (DAB) $\mathrm{PbBr}_{4}$ and (EDBE) $\mathrm{PbBr}_{4}$.

Figure S10 Comparison between the PL and XL spectra at $290 \mathrm{~K}$.

Table S2 Decay components and their averages for the time-resolved PL (TRPL) and timeresolved XL (TRXL) of the 2D-perovskites.

Table S3 Afterglow decay time of the 2D-perovskites

Figure S11 Example from the fitting of the thermoluminescence (TL) curve for $(\mathrm{OA})_{2} \mathrm{PbBr}_{4}$ 
Table S4 Trap energies and their widths from the fitting of the afterglow curves.

Figure S12 XL spectra with direct comparison intensities for all the 2D-perovskites.

Figure S13 Pulse-height spectra for undoped and Li-doped (PEA) $)_{2} \mathrm{PbBr}_{4}$.

Figure S14 Pulse height spectra under various gamma-ray excitation and their nonproportionality of light yields and energy resolutions from $(\mathrm{BA})_{2} \mathrm{PbBr}_{4}$.

Figure $\mathrm{S} 15$ Time-resolved $\mathrm{PL}$ for $(\mathrm{BA})_{2} \mathrm{PbI}_{4}$. and $(\mathrm{OA})_{2} \mathrm{PbI}_{4}$ at room temperature $(\mathrm{RT})$ and $100 \mathrm{~K}$ 
Table S1. Concise formula, molecular formula, volume, mass density, and atomic effective numbers for our 2D perovskite halide crystals. The references for those crystals are also can be found in Table 1 of the main manuscript.

\begin{tabular}{|c|c|c|c|c|c|c|c|}
\hline \multirow[t]{2}{*}{$\begin{array}{l}\text { Concise } \\
\text { formula }\end{array}$} & \multirow[t]{2}{*}{ Molecular formula } & \multicolumn{2}{|c|}{ Volume $\left(\mathrm{A}^{3}\right)$} & \multicolumn{2}{|c|}{$\begin{array}{l}\text { Mass density } \\
\left(\mathrm{g} / \mathrm{cm}^{3}\right)\end{array}$} & \multicolumn{2}{|c|}{$\begin{array}{l}\text { Atom. Effect. } \\
\text { Number }\end{array}$} \\
\hline & & Bromide & Iodide & Bromide & Iodide & Bromide & Iodide \\
\hline$(\mathrm{BA})_{2} \mathrm{PbX}_{4}$ & $\left(\mathrm{CH}_{3}\left(\mathrm{CH}_{2}\right)_{3} \mathrm{NH}_{3}\right)_{2} \mathrm{PbX}_{4}$ & 1840.34 & 2094.34 & 2.437 & 2.736 & 33.85 & 37.45 \\
\hline$(\mathrm{CHA})_{2} \mathrm{PbX}_{4}$ & $\left(\mathrm{C}_{6} \mathrm{H}_{11} \mathrm{NH}_{3}\right)_{2} \mathrm{PbX}_{4}$ & 2031.50 & 2238.00 & 2.378 & 2.716 & 32.31 & 35.75 \\
\hline$(\mathrm{DAB}) \mathrm{PbX}_{4}$ & $\mathrm{H}_{3} \mathrm{~N}\left(\mathrm{CH}_{2}\right)_{4} \mathrm{NH}_{3} \mathrm{PbX}_{4}$ & 1362.45 & 1550.49 & 3.008 & 3.376 & 37.83 & 41.86 \\
\hline$(\mathrm{OA})_{2} \mathrm{PbX}_{4}$ & $\left(\mathrm{CH}_{3}\left(\mathrm{CH}_{2}\right)_{7} \mathrm{NH}_{3}\right)_{2} \mathrm{PbX}_{4}$ & 2635.22 & 2925.24 & 2.052 & 2.215 & 30.03 & 33.22 \\
\hline$(\mathrm{API}) \mathrm{PbX}_{4}$ & $\mathrm{C}_{3} \mathrm{~N}_{2} \mathrm{H}_{3}\left(\mathrm{CH}_{2}\right)_{3} \mathrm{NH}_{3} \mathrm{PbX}_{4}$ & 1432.85 & 1630.61 & 3.032 & 3.404 & 33.43 & 36.99 \\
\hline (AEIU)PbX $\mathrm{Pb}_{4}$ & $\mathrm{H}_{3} \mathrm{NCNHS}\left(\mathrm{CH}_{2}\right)_{2} \mathrm{NH}_{3} \mathrm{PbX}_{4}$ & 1362.06 & 1550.05 & 3.16 & 3.546 & 38.64 & 42.75 \\
\hline$(\mathrm{EDBE}) \mathrm{PbX}_{4}$ & $\mathrm{C}_{6} \mathrm{H}_{18} \mathrm{O}_{2} \mathrm{~N}_{2} \mathrm{PbX}{ }_{4}$ & 1557.09 & 1772.00 & 2.888 & 3.242 & 35.29 & 39.05 \\
\hline$(\mathrm{PEA})_{2} \mathrm{PbX}_{4}$ & $\left(\mathrm{C}_{6} \mathrm{H}_{5}\left(\mathrm{CH}_{2}\right)_{2} \mathrm{NH}_{3}\right)_{2} \mathrm{PbX}_{4}$ & 2250.60 & 2498.29 & 2.362 & 2.550 & 32.31 & 35.75 \\
\hline
\end{tabular}




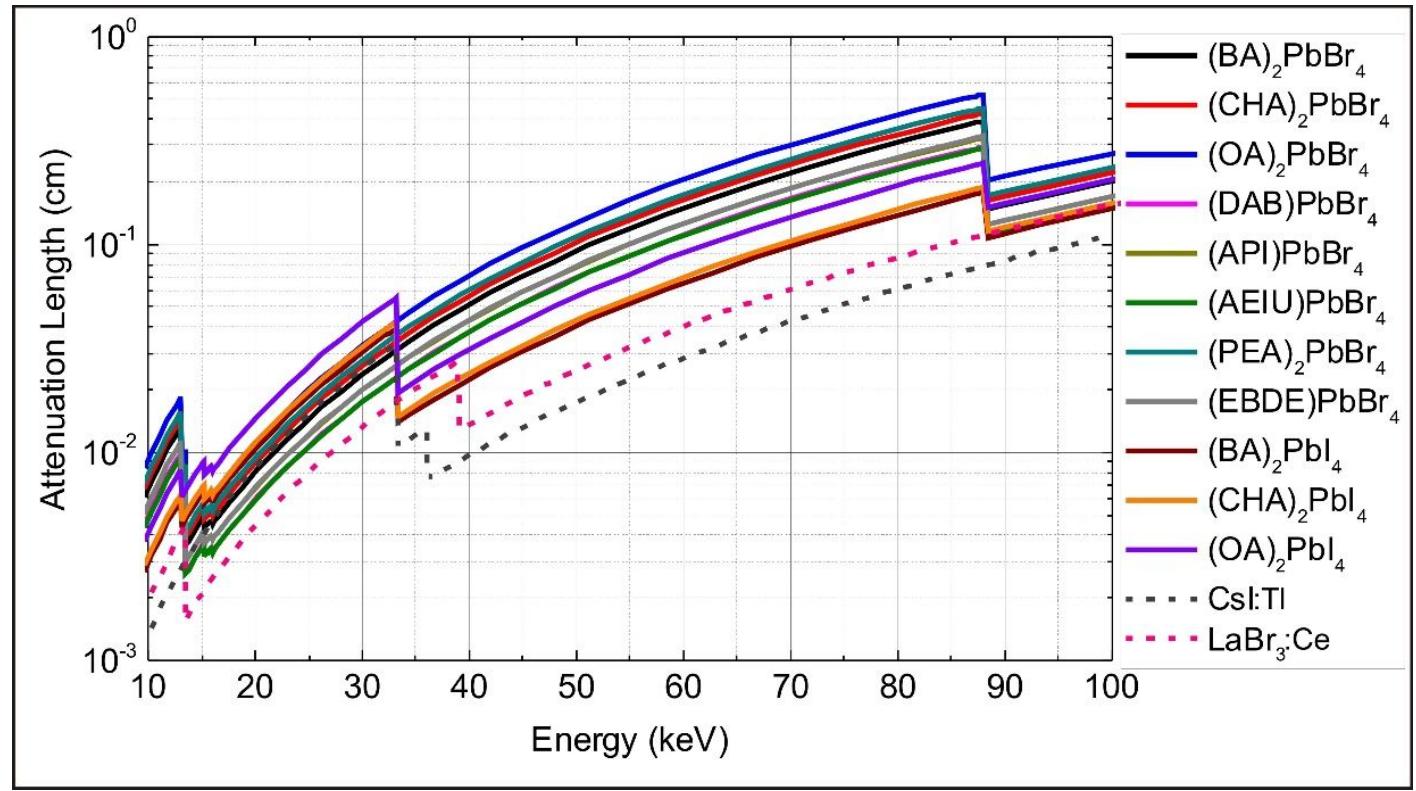

Figure S1. Attenuation length of the investigated 2D perovskites and two commercial scintillators, CsI:Tl and $\mathrm{LaBr}_{3}: \mathrm{Ce}$. Due to the presence of lead, the $2 \mathrm{D}$ perovskites have relatively short attenuation length, in the same order of magnitude of the fully inorganic commercial scintillators. 

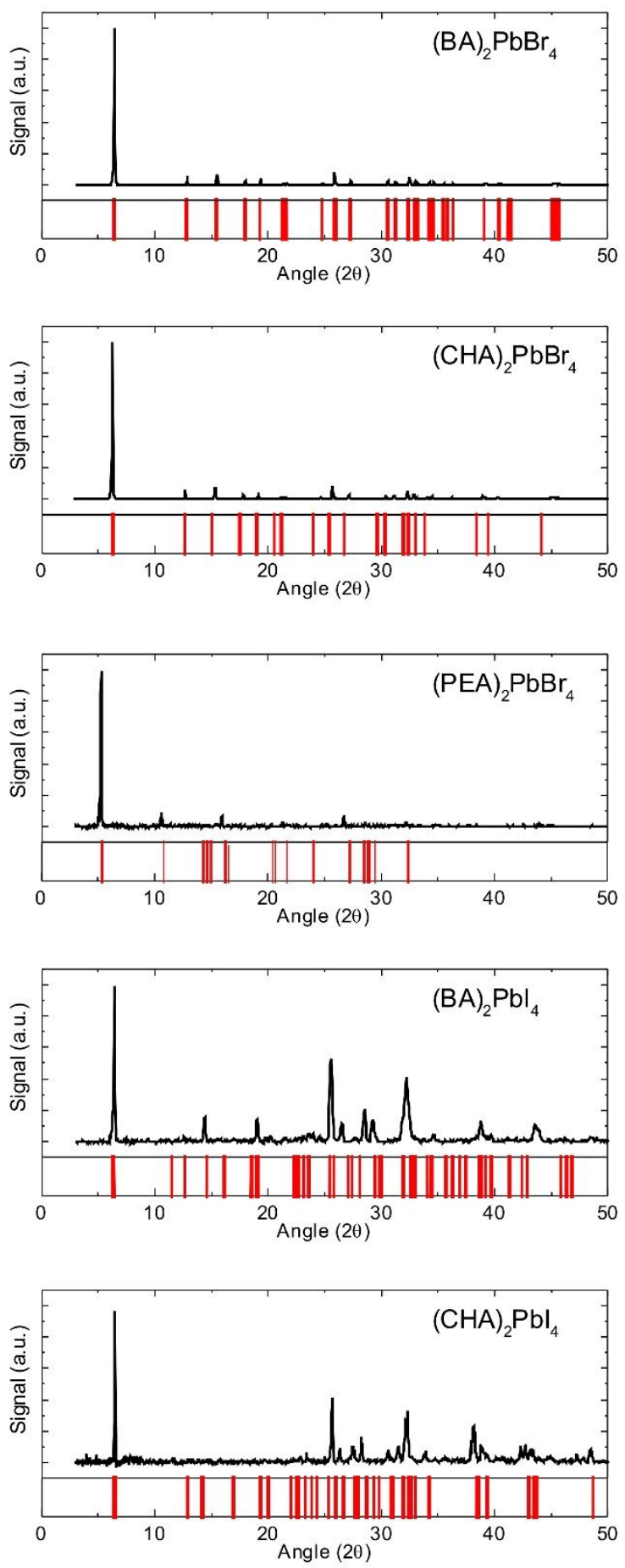

Figure S2: X-ray diffraction patterns (black) of some investigated the two-dimensional (2D) perovskite crystals, $(\mathrm{BA})_{2} \mathrm{PbBr}_{4},(\mathrm{CHA})_{2} \mathrm{PbBr}_{4},(\mathrm{PEA})_{2} \mathrm{PbBr}_{4},(\mathrm{BA})_{2} \mathrm{PbI}_{4},(\mathrm{CHA})_{2} \mathrm{PbI}_{4}$, and the theoretical XRD lines (red), showing in particular the correspondence to the first Braggreflection peak. ${ }^{1-4}$ 


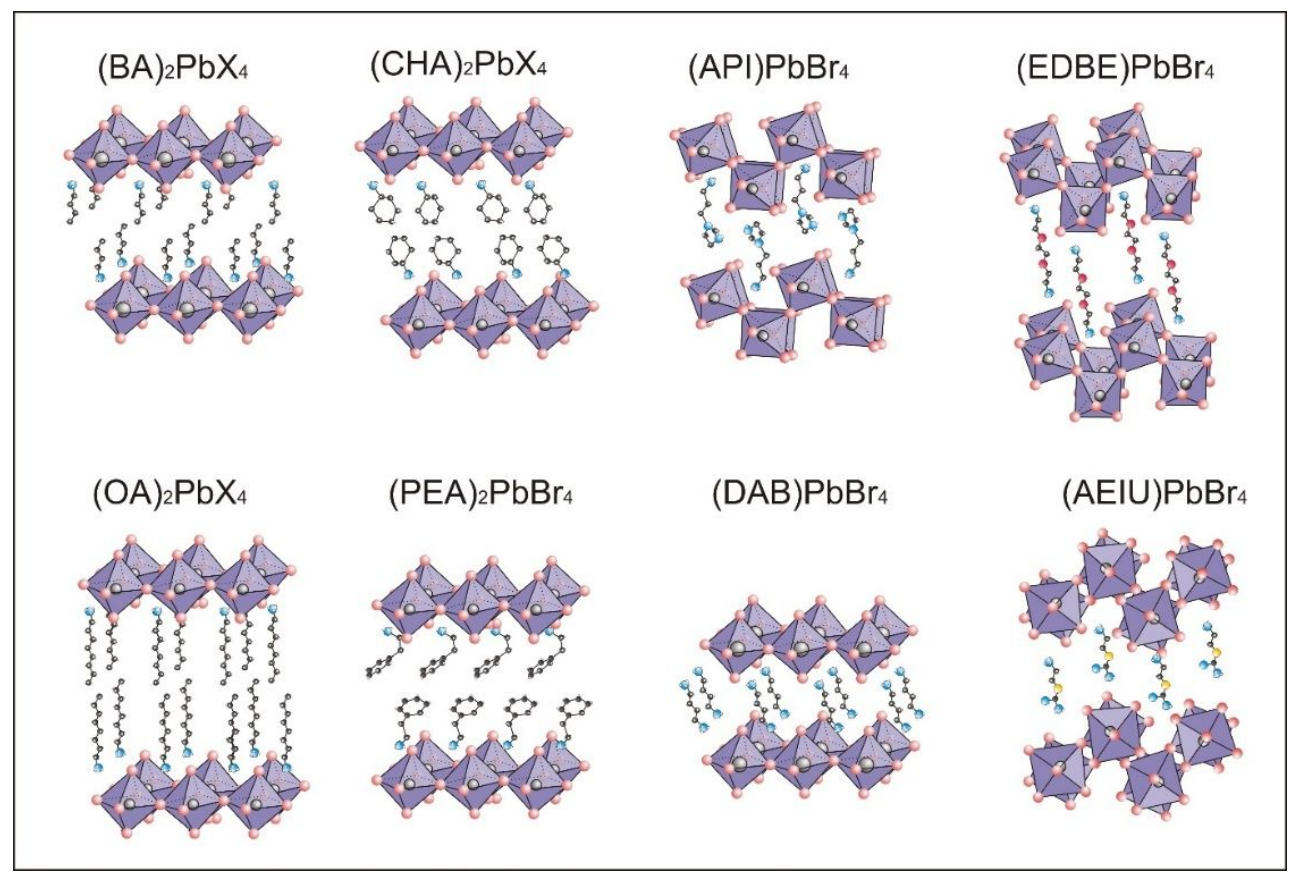

Figure S3: Schematic representation of the structure of the investigated two-dimensional perovskites.

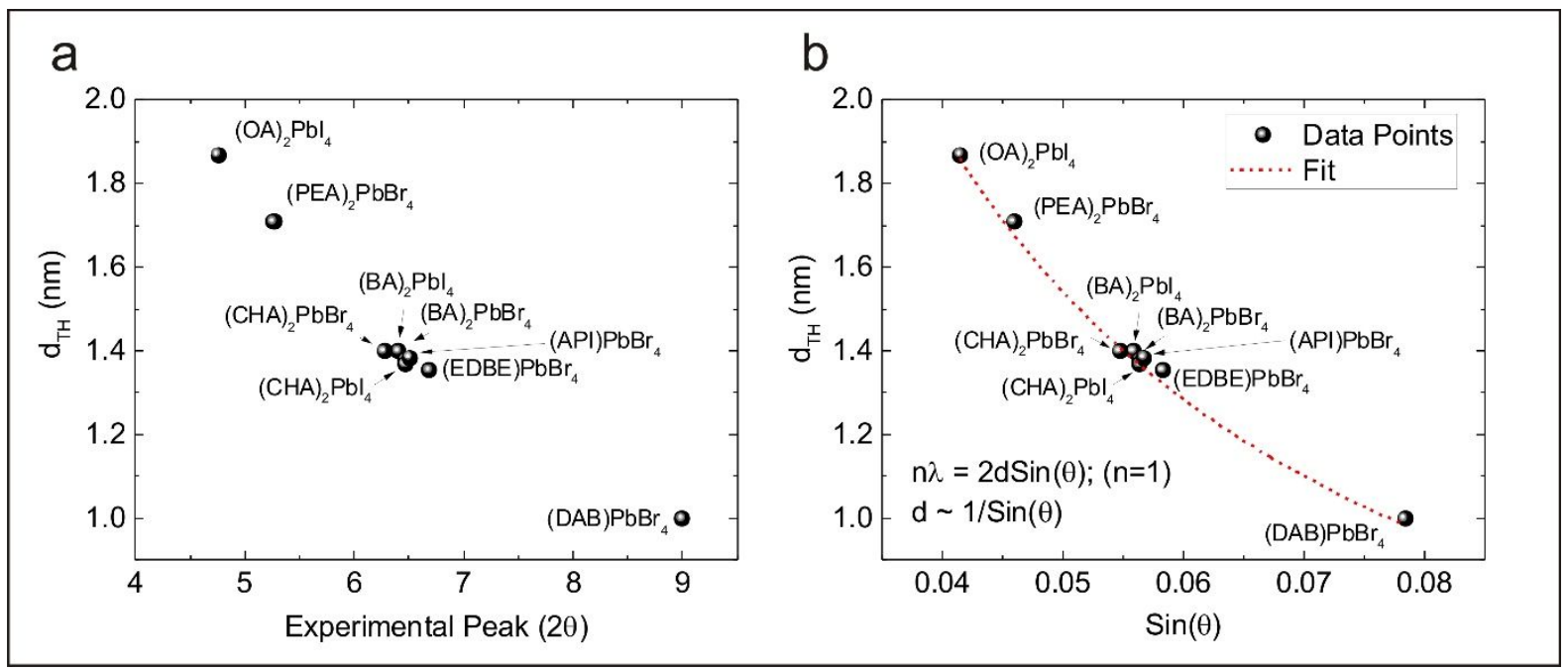

Figure S4: a) Interlayer distances (d) of some of the investigated perovskites vs. the angle $(\theta)$ experimental peak. b) The interlayer distances vs. the sine of the experimentally measured angle. The red line is the fit with $\mathrm{d}=\mathrm{A} / \sin (\theta)$, where $\mathrm{A}=\lambda / 2=0.077 \mathrm{~nm}$, with $\lambda$ being the X-ray wavelength used in the experiment (Cu K- $\alpha$ emission). ${ }^{1-9}$ 
Further discussion on the role of the cations in two-dimensional perovskites. The main impact of the cation on the properties of the two-dimensional perovskite is by the manner that the cation affects the shape and orientation of the $\left[\mathrm{PbX}_{6}^{4-}\right]$-octahedra layers. It is ultimately the conformation of the lead halide octahedra layers that determines most of the photoluminescence (PL) and radioluminescence properties of the perovskite. The conformation of the inorganic octahedra layers mainly depends on the arrangement of the cations in the structure. The linear ammonium cations (BA, DAB, OA) seem to orient themselves in flat bilayers (for BA and $\mathrm{OA})^{2,4,6}$ or monolayers (for $\left.\mathrm{DAB}\right)^{4}$ and thus result into a (100)-oriented flat structure of the lead halide layers, resulting in a very similar emission spectrum, with a relatively narrow blue (peaking at 400-430 $\mathrm{nm}$ ) emission for the bromide variants and a green emission (peaking at $525 \mathrm{~nm}$ ) for the iodide variant. Comparing the emissions of DAB, BA and OA, which have progressively larger distance between the lead-halide octahedra layers, the difference in emission seems to be rather small, in particular when comparing the longer OA-cation and the shorter DAB-cation. This might indicate that the organic cations act as spacers between the octahedra layers which are independent of each other. The small differences observed are thus due to the distortions and/or tilting relative to the plane of the octahedra in the lead halide layers in the crystals. Shorter linear alkyl cations (propyl, ethyl, which are not investigated in this work) have been reported in literature to form (110)-oriented corrugations and nanobelts, which lead to much broader and red-shifted emissions, ${ }^{10-11}$ while intermediate and longer linear alkyl chains than the ones used in this work (up octadecyl ammonium cations which are twice as long as the OA-cation) have been reported to maintain the 100 -flat structure and a blue emission (peaking at $400-430 \mathrm{~nm}$ ). ${ }^{12}$ The aromatic PEA-cation also forms flat bilayers; therefore, it is leading to (100) -oriented flat octahedra layers as well, and it presents a similar emission profile to the linear alkyl perovskites. ${ }^{3}$ The $\mathrm{CHA}$-cation also forms flat layers. However, it has been reported in the literature that the CHA-cation leads to 
significantly tilting of octahedra relative to the plane of the layers, ${ }^{1,5}$ which can give rise to self-trapped excitons and thus probably responsible for the much broader emission we observe in the $(\mathrm{CHA})_{2} \mathrm{PbX}_{4}$ perovskites. The API, AEIU and EDBE cations, as previously mentioned, cause the lead-halide octahedra to exhibit a (110) -oriented corrugated structure ${ }^{7-9}$ that can give rise to self-trapped excitons, which leads to the red shifted and generally very broad emissions observed, ${ }^{10-11}$ leading even to white light emission spectra. It is important to note that the photoluminescent properties of the cation itself do not appear to have a significant impact on the PL and radioluminescence properties of the perovskites and are negligible compared to the emission of the inorganic layers.

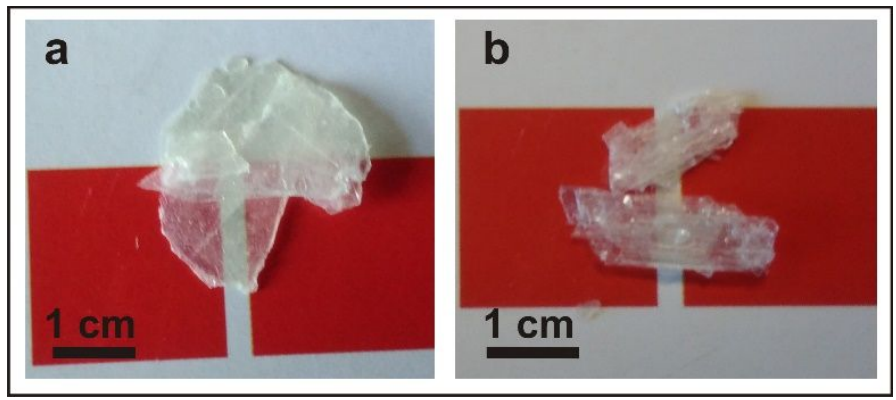

Figure S5: Centimeter size crystals for a) $(\mathrm{PEA})_{2} \mathrm{PbBr}_{4}$ and b) $(\mathrm{BA})_{2} \mathrm{PbBr}_{4}$. 


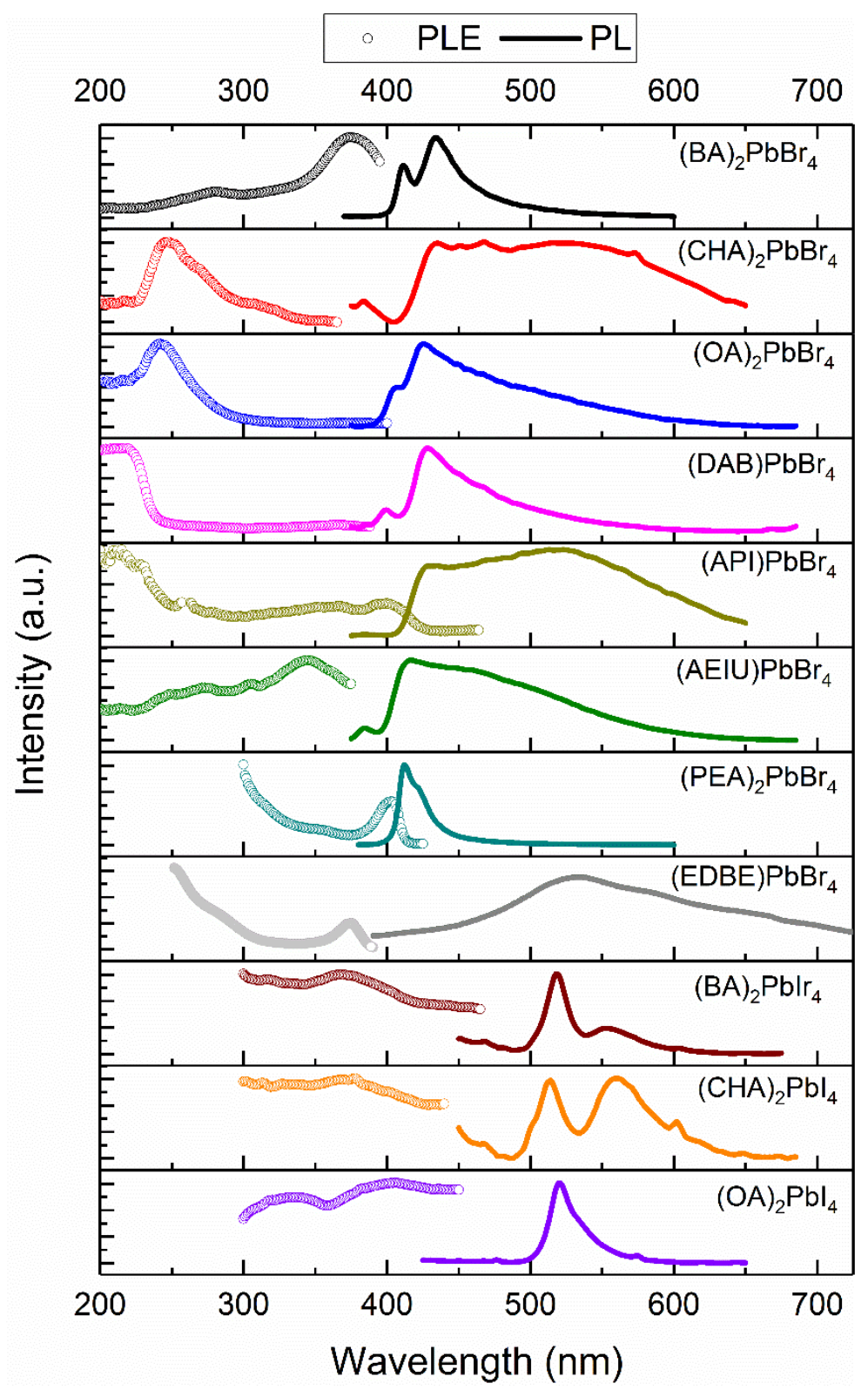

Figure S6. PL excitation spectra of the investigated 2D perovskites taken at the peak of emission wavelength and PL spectra excited at 260 and $400 \mathrm{~nm}$ for bromide and iodide crystals, respectively. 


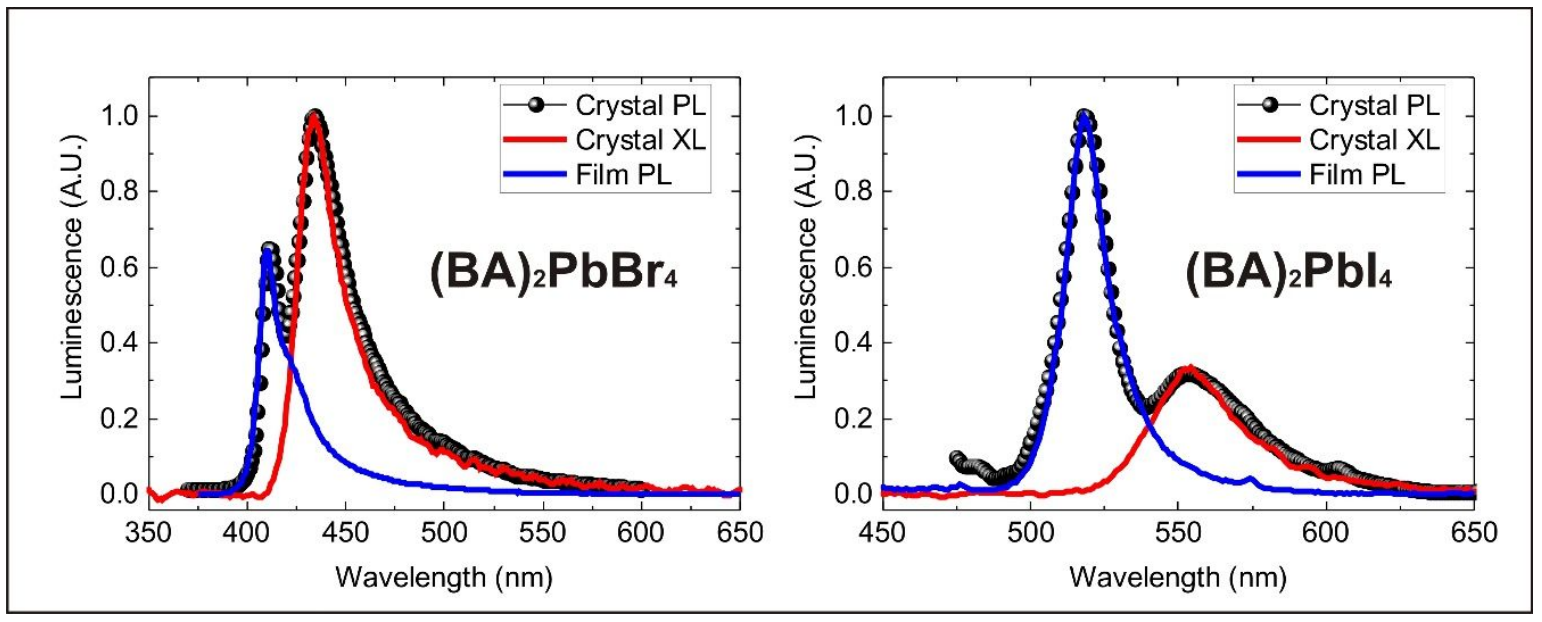

Figure S7. PL, XL of bulk crystal and nano-crystalline films of $(\mathrm{BA})_{2} \mathrm{PbBr}_{4}$ and $(\mathrm{BA})_{2} \mathrm{PbI}_{4}$.

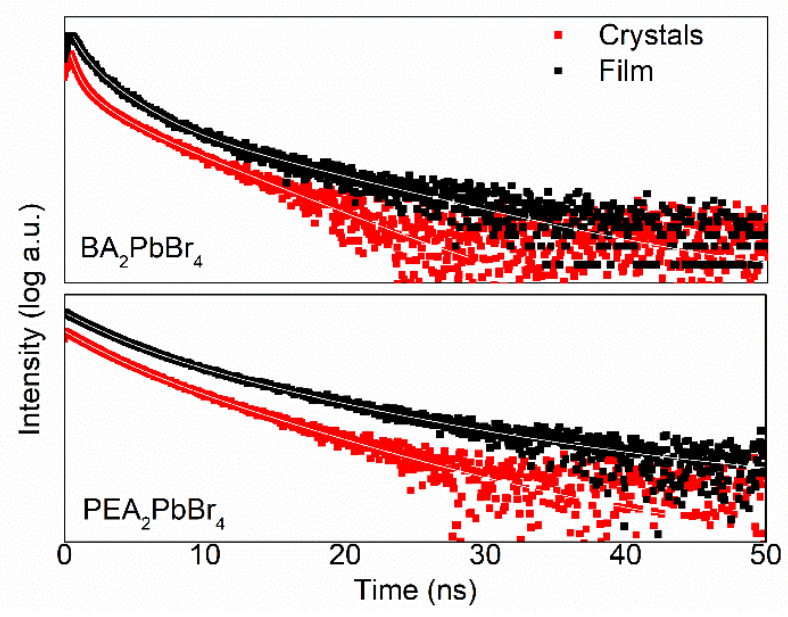

Figure S8. Time resolved PL of single crystals and thin films $(\sim 70 \mu \mathrm{m})$ of $(\mathrm{BA})_{2} \mathrm{PbBr}_{4}$ and $(\mathrm{PEA})_{2} \mathrm{PbBr}_{4}$ with excitation at $266 \mathrm{~nm}$ with monitoring emission at $425 \mathrm{~nm}$. The decay times of the films are faster than those of single crystals. The respective decay components (and \% contributions) for $(\mathrm{BA})_{2} \mathrm{PbBr}_{4}$ and $(\mathrm{PEA})_{2} \mathrm{PbBr}_{4}$ thin films are $0.4(24 \%), 1.5(32 \%), 4.8 \mathrm{~ns}$ (44\%) and $2.3(34 \%), 5.4(61 \%), 12.0(5 \%)$. The average decay times are 2.7 and $4.6 \mathrm{~ns}$ for $(\mathrm{BA})_{2} \mathrm{PbBr}_{4}$ and $(\mathrm{PEA})_{2} \mathrm{PbBr}_{4}$ thin films, respectively. They are slightly faster than those in crystals (Table 1). 


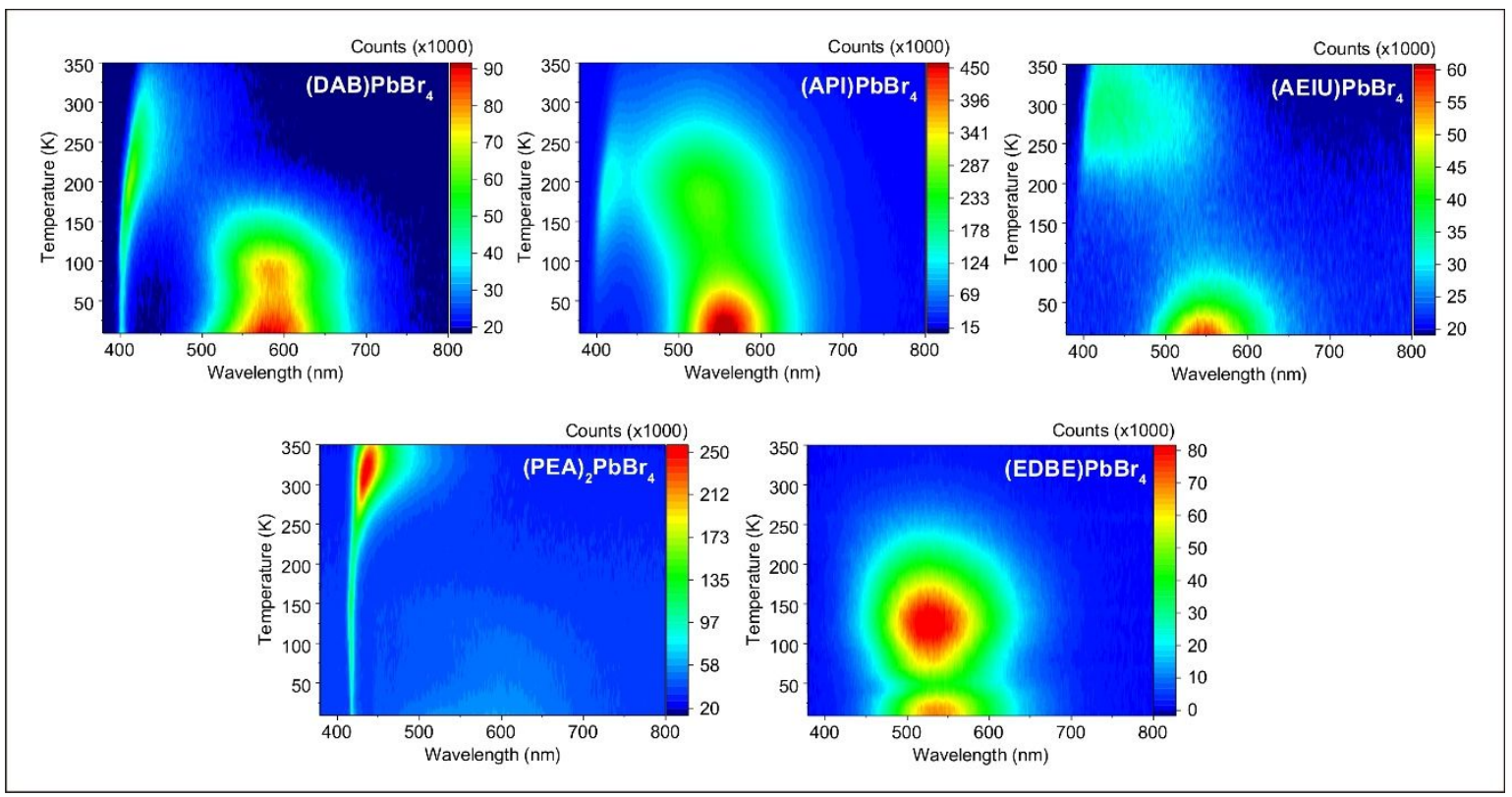

Figure S9. Temperature-dependent $\mathrm{XL}$ of (DAB) $\mathrm{PbBr}_{4}, \quad(\mathrm{API}) \mathrm{PbBr}_{4}, \quad(\mathrm{AEIU}) \mathrm{PbBr}_{4}$, $(\mathrm{PEA})_{2} \mathrm{PbBr}_{4}$, and (EDBE) $\mathrm{PbBr}_{4}$. 


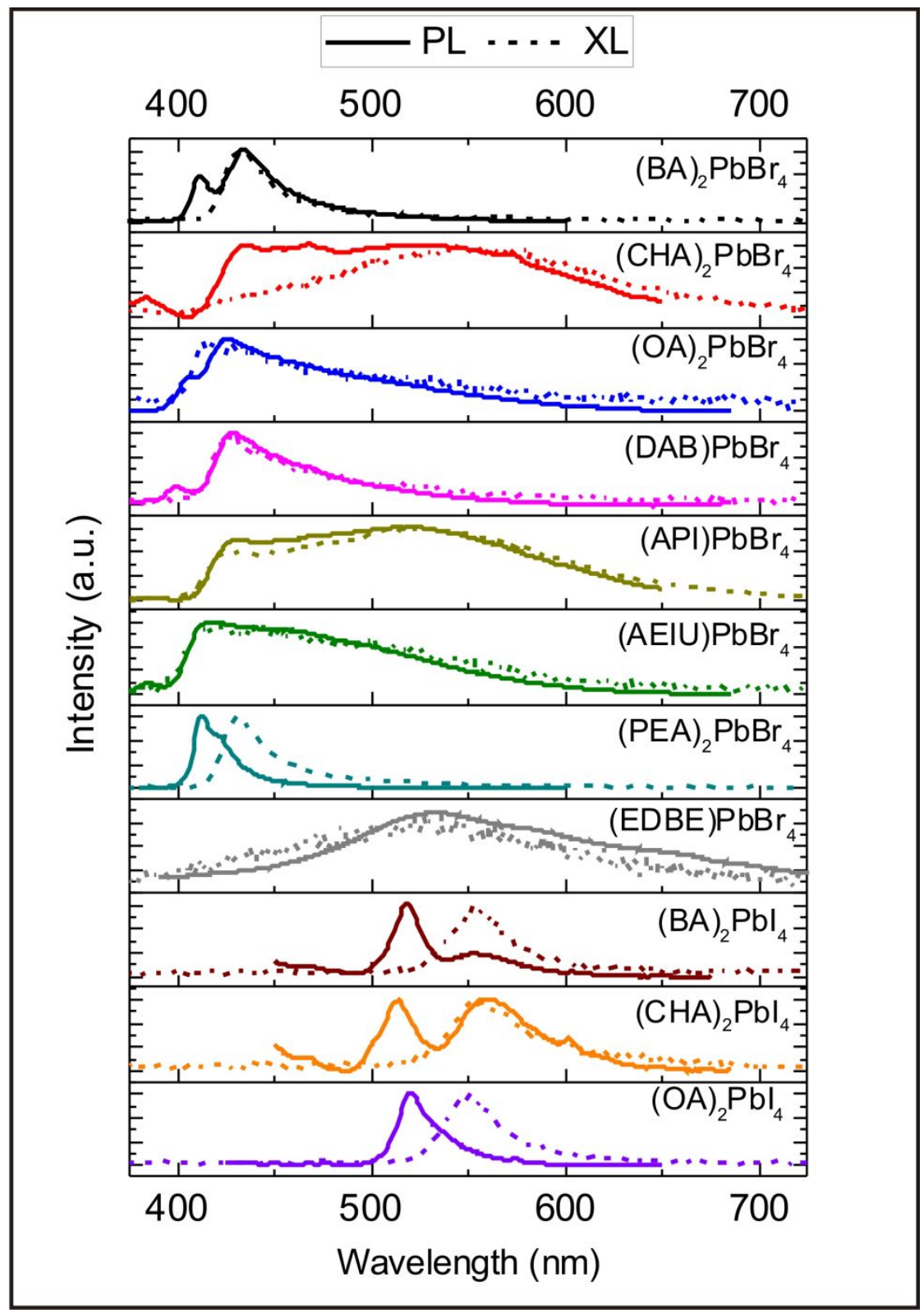

Figure S10. Comparison between the PL and XL spectra at $290 \mathrm{~K}$. 
Table S2. Decay components, their averages and their contributions from three-exponential fits of time-resolved PL (TRPL) and time-resolved XL (TRXL). The values of components and averages are in nanoseconds.

\begin{tabular}{|c|c|c|}
\hline \multirow[t]{2}{*}{ Compounds } & \multicolumn{2}{|c|}{ Decay components (\%) [Average] } \\
\hline & TRPL & TRXL \\
\hline \multirow{2}{*}{$(\mathrm{BA})_{2} \mathrm{PbBr}_{4}$} & $0.7(33 \%), 2.2(47 \%), 7.8(20 \%)$ & $1.3(12 \%), 4.5(81 \%), 20.8(7 \%)$ \\
\hline & [2.8] & [5.3] \\
\hline \multirow{2}{*}{$(\mathrm{CHA})_{2} \mathrm{PbBr}_{4}$} & $1.0(13 \%), 2.9(68 \%), 9.2(19 \%)$ & $0.4(4 \%), 1.9(33 \%), 5.5(63 \%)$ \\
\hline & [3.9] & [4.1] \\
\hline \multirow{2}{*}{$(\mathrm{OA})_{2} \mathrm{PbBr}_{4}$} & $0.3(43 \%), 0.4(43 \%), 2.5(14 \%)$ & $0.2(15) 0.6(42 \%) 1.9(43 \%)$ \\
\hline & {$[0.7]$} & {$[1.1]$} \\
\hline \multirow{2}{*}{$(\mathrm{DAB}) \mathrm{PbBr}_{4}$} & $0.4(43 \%), 0.5(44 \%), 4.9(13 \%)$ & $0.4(13 \%), 1.6(32 \%), 7.1(55 \%)$ \\
\hline & [1.0] & [4.5] \\
\hline \multirow{2}{*}{$(\mathrm{API}) \mathrm{PbBr}_{4}$} & $1.5(26 \%), 4.0(59 \%), 9.6(15 \%)$ & $1.4(6 \%), 5.5(36 \%), 17.3(58 \%)$ \\
\hline & [4.2] & {$[12.1]$} \\
\hline \multirow{2}{*}{$(\mathrm{AEIU}) \mathrm{PbBr}_{4}$} & $0.7(46 \%), 2.5(37 \%), 10.3(17 \%)$ & $0.5(4 \%), 2.2(29 \%), 6.9(67 \%)$ \\
\hline & {$[3.0]$} & {$[5.2]$} \\
\hline \multirow{2}{*}{$(\mathrm{PEA})_{2} \mathrm{PbBr}_{4}$} & $2.6(37 \%) 6.9(54 \%) 19.2(9 \%)$ & $1.1(2 \%), 5.0(22 \%), 14.6(76 \%)$ \\
\hline & {$[6.4]$} & [12.3] \\
\hline \multirow{2}{*}{$(\mathrm{EDBE}) \mathrm{PbBr}_{4}$} & $0.3(2 \%), 0.4(2 \%), 12.9(96 \%)$ & $1.1(5 \%), 17.0(88 \%), 36.0(7 \%)$ \\
\hline & {$[12.4]$} & {$[17.0]$} \\
\hline \multirow{2}{*}{$(\mathrm{BA})_{2} \mathrm{PbI}_{4}$} & $0.3(3 \%), 0.5(89 \%), 1.0(8 \%)$ & $0.3(49 \%), 1.3(47 \%), 2.1(4 \%)$ \\
\hline & {$[0.5]$} & {$[0.8]$} \\
\hline \multirow{2}{*}{$(\mathrm{CHA})_{2} \mathrm{PbI}_{4}$} & $0.3(9 \%), 1.0(85 \%), 9.7(6 \%)$ & $0.3(21 \%), 1.5(75 \%), 8.3(4 \%)$ \\
\hline & [1.4] & [1.5] \\
\hline \multirow{2}{*}{$(\mathrm{OA})_{2} \mathrm{PbI}_{4}$} & $0.4(36 \%), 0.6(59 \%), 1.6(5 \%)$ & $0.3(49 \%), 0.9(43 \%), 2.0(8 \%)$ \\
\hline & {$[0.6]$} & {$[0.6]$} \\
\hline
\end{tabular}


Afterglow curve fits. We fitted the intensity $(I)$ in Figure 4 a with single, double, or three exponential decay components.

$$
\left.I=\sum_{i=1}^{n}\left(A_{i} e^{-\frac{t}{t_{i}}}\right), n=1 \text { or } 2 \text { or } 3 \text { (Equation } \mathrm{S} 1\right)
$$

and the contribution $\left(C_{i}\right)$ of each decay components $\left(t_{i}\right)$ is calculated as following

$$
C_{i}=\frac{A_{i} \times t_{i}}{\sum_{i=1}^{n} A_{i} \times t_{i}^{\prime}}, n=1 \text { or } 2 \text { or } 3
$$

We also measured the average afterglow lifetimes $(\bar{t})$ through the multiplication of decay components and their contributions.

$$
\bar{t}=\sum_{i=1}^{n} C_{i} \times t_{i}, n=1 \text { or } 2 \text { or } 3 \quad \text { (Equation S3) }
$$

Table S3. Afterglow decay time.

\begin{tabular}{|l|c|c|}
\hline \multicolumn{1}{|c|}{ Perovskites } & $t_{i}(\mathrm{~s}) / C_{i}(\%)$ & $\bar{t}(\mathrm{~s})$ \\
\hline$(\mathrm{BA})_{2} \mathrm{PbBr}_{4}$ & Not observed & Not observed \\
\hline$(\mathrm{CHA})_{2} \mathrm{PbBr}_{4}$ & $17.9 \mathrm{~s} / 100 \%$ & $17.9 \mathrm{~s}$ \\
\hline$(\mathrm{OA})_{2} \mathrm{PbBr}_{4}$ & $38.2 \mathrm{~s} / 83 \% ; 290.6 \mathrm{~s} / 17 \%$ & $63.8 \mathrm{~s}$ \\
\hline$(\mathrm{DAB}) \mathrm{PbBr}_{4}$ & Not observed & Not observed \\
\hline$(\mathrm{API}) \mathrm{PbBr}_{4}$ & $30.7 \mathrm{~s} / 100 \%$ & $296.7 \mathrm{~s}$ \\
\hline$(\mathrm{AEIU}) \mathrm{PbBr}_{4}$ & $51.0 \mathrm{~s} / 20 \% ; 357.5 / 80 \%$ & Not observed \\
\hline$(\mathrm{PEA})_{2} \mathrm{PbBr}_{4}$ & $12.2 \mathrm{~s} / 18 \% ; 69.7 \mathrm{~s} / 29 \% ;$ & $299.2 \mathrm{~s}$ \\
\hline$(\mathrm{EDBE}) \mathrm{PbBr}_{4}$ & $522.3 / 53 \%$ & Not observed \\
\hline$(\mathrm{BA})_{2} \mathrm{PbI}_{4}$ & Not observed & Not observed \\
\hline$(\mathrm{CHA})_{2} \mathrm{PbI}_{4}$ & Not observed & $281.5 \mathrm{~s}$ \\
\hline$(\mathrm{OA})_{2} \mathrm{PbI}_{4}$ & $21.9 \mathrm{~s} / 7 \% ; 301.0 \mathrm{~s} / 93 \%$ & $2 \%$ 年 \\
\hline
\end{tabular}


Glow peak fits. We assume that all of traps which are occurring in TL spectra can be represented as quasi-continuous trap distributions. In order to determine the trap parameters (including quasi-continuous trap distributions), we use the procedure described by Brylew et al. ${ }^{13}$ assuming arbitrary value of the frequency factor for distribution at $10^{11} \mathrm{~s}^{-1}$. The example of the fit procedures is shown in Fig. S5 while the traps parameters obtained from the fitting procedure are given in Table S4.

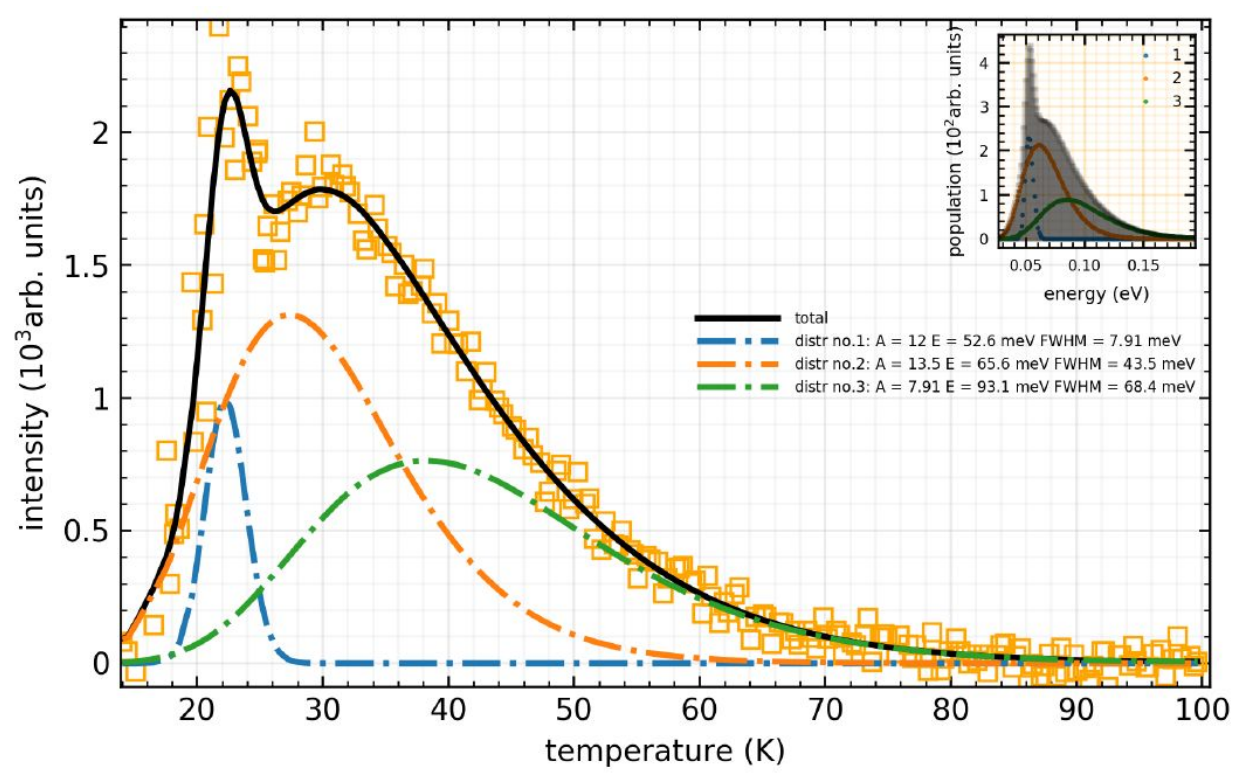

Figure S11. An example fitting procedure for glow peak of $(\mathrm{OA})_{2} \mathrm{PbBr}_{4}$ for three trap depths. 
Table S4. Trap parameters including the trap depth $\left(E_{t}\right)$ and full width half maximum $(F W H M)$ energies obtained from the fit.

\begin{tabular}{|l|c|c|c|c|}
\hline \multirow{2}{*}{ Perovskites } & \multicolumn{3}{|c|}{$E_{t}(\mathrm{meV}) / F W H M(\mathrm{meV})$} \\
\cline { 2 - 5 } & Trap 1 & Trap 2 & Trap 3 & - \\
\hline$(\mathrm{BA})_{2} \mathrm{PbBr}_{4}$ & - & - & - & - \\
\hline$(\mathrm{CHA})_{2} \mathrm{PbBr}_{4}$ & $113.4 / 25.5$ & $162.8 / 59.3$ & $93.1 / 68.4$ & - \\
\hline$(\mathrm{OA})_{2} \mathrm{PbBr}_{4}$ & $52.6 / 7.9$ & $65.6 / 43.5$ & - & - \\
\hline$(\mathrm{DAB}) \mathrm{PbBr}_{4}$ & - & - & $249 / 125$ & - \\
\hline$(\mathrm{API}) \mathrm{PbBr}_{4}$ & $54.0 / 12.7$ & $80.1 / 71.3$ & - & - \\
\hline$(\mathrm{AEIU}) \mathrm{PbBr}_{4}$ & $78.0 / 50.0$ & - & - & $110 / 18.2$ \\
\hline$(\mathrm{PEA})_{2} \mathrm{PbBr}_{4}$ & - & - & $70.0 / 16.3$ & - \\
\hline$(\mathrm{EDBE}) \mathrm{PbBr}_{4}$ & $20.0 / 9.2$ & $30.0 / 11.6$ & - & - \\
\hline$(\mathrm{BA})_{2} \mathrm{PbI}_{4}$ & - & - & - & - \\
\hline$(\mathrm{CHA})_{2} \mathrm{PbI}_{4}$ & $69.30 / 24.50$ & - & & - \\
\hline$(\mathrm{OA})_{2} \mathrm{PbI}_{4}$ & $62.5 / 24.7$ & $94.7 / 101$ & & - \\
\hline
\end{tabular}




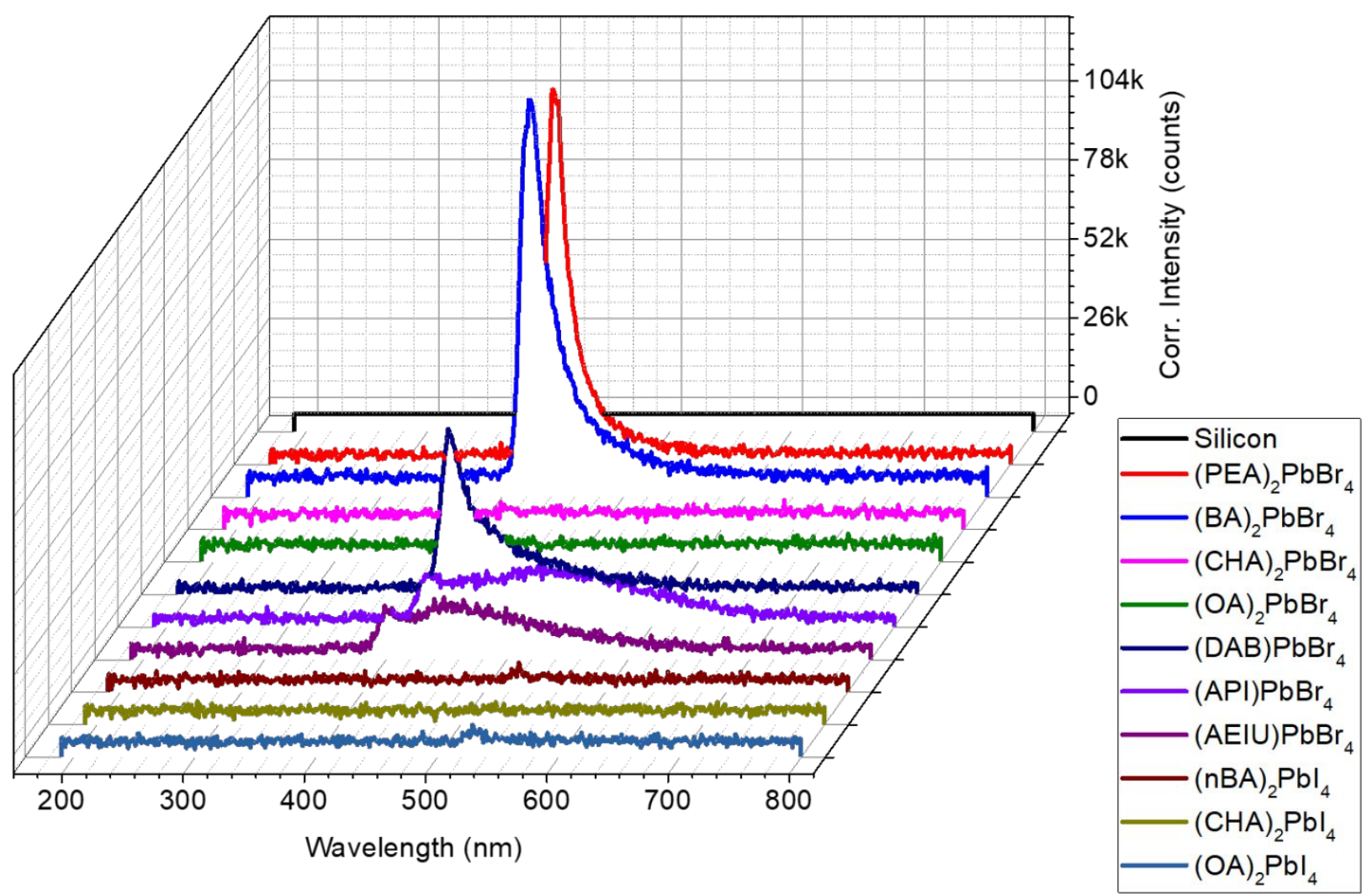

Figure S12. XL spectra with direct comparison intensities among all 2D perovskite crystals. For this experiment, the samples were prepared with the same size, the measurements were initiated with the same setting for $\mathrm{X}$-ray generator $(\mathrm{Cu}$-anode tube, $8.04 \mathrm{keV}$ at $45 \mathrm{kV}$ and 10 $\mathrm{mA}$ ), and performed at the same day. 
Light yield. We obtained light yields from the position of the $662 \mathrm{keV}$ photopeak in pulse height spectra both recorded with the PMT. Using the PMT, the photoelectron yield $\left(Y_{p e}\right)$, expressed in photoelectrons per $\mathrm{MeV}$ of absorbed $\gamma$-ray energy (phe/MeV), is determined by comparing of the peak position of the $662 \mathrm{keV}$ photopeak to the position of the mean value of the single electron response. The single electron response spectrum is shown in Figure S13a. The method to obtain the mean value of the single electron response can be found in the work of Dossi et al. 2000. ${ }^{14}$ It was estimated in Refs. [deHaas2005, deHaas2008] ${ }^{15-16}$ that the position of the mean value of the single electron response is about $13 \%$ lower than the position of the top of the Gaussian function, see Figure S13a. The position as well as the energy resolution (full width at half maximum/position) of a photopeak is determined by fitting the photopeak with a Gaussian curve, see Figure S13b.

The absolute photon yield $Y_{p h}$ in photons per $\mathrm{MeV}$ is derived from $Y_{p e}$ as follows ${ }^{15}$ :

$$
Y_{p h}=\frac{Y_{p e}}{Q E_{e f f}}
$$

where $Q E_{\text {eff }}$ is the effective quantum efficiency of the PMT and grating obtained from the manufacturer. It is averaged over the profile of the X-ray excited emission spectra.

As an example of the complete pulse height spectrum, we calculate the light yield of the undoped, and Li doped (PEA) ${ }_{2} \mathrm{PbBr}_{4}$ crystals in respective Figures $\mathrm{S} 13 \mathrm{~b}$ and $\mathrm{S} 13 \mathrm{c}$ as following. The position of the mean value from single electron response is at channel of 72 while the positions of the photopeaks $x_{p e}$ at $1150 \pm 59$ and $2270 \pm 87$ for undoped and Li doped $(\mathrm{PEA})_{2} \mathrm{PbBr}_{4}$ crystals, respectively. The positions at $1052 \pm 43$ and $2039 \pm 88$ correspond to the escape peaks of undoped and Li doped crystals, respectively, due to K-shell absorption edge of lead. They are shifted by $72 \mathrm{keV}$ at lower energy than the $662 \mathrm{keV}$ photopeaks. The single electron response was measured at gain of 300 while the pulse height spectra of ${ }^{137} \mathrm{Cs}$ were at a gain of 3 . Therefore, $Y_{p e}$ for both samples should follow $\left(x_{p e} / 72\right) \times(300 / 3)$ and they 
are equal to $1,600 \pm 100$ and 3,200 \pm 100 phe/MeV for undoped and Li doped crystals, respectively. We obtain $Q E_{\text {eff }}$ for our Hamamatsu R878 PMT of $14 \%$ at the emission wavelength and the light yield of undoped and Li doped $\mathrm{PEA}_{2} \mathrm{PbBr}_{4}$ crystals are $11,400 \pm 700$ and 22,900 \pm 700 photons/MeV, respectively.
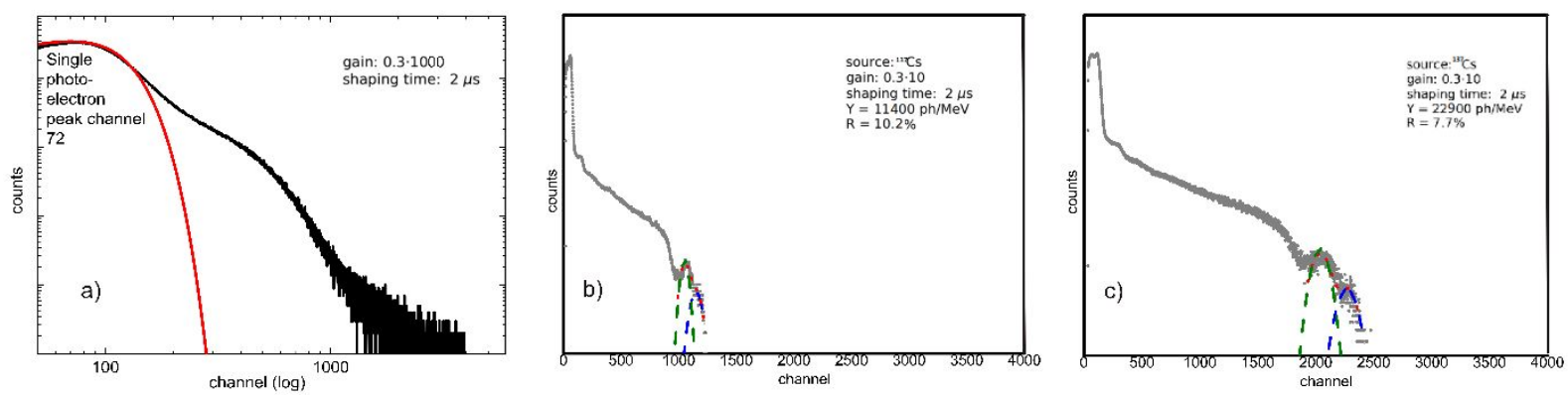

Figure S13. a) Measured single electron response of the Hamamatsu R878 PMT. b, c) Pulse height spectra under gamma-ray excitation of ${ }^{137} \mathrm{Cs}$ source at $662 \mathrm{keV}$ for b) undoped and c) Li doped $(\mathrm{PEA})_{2} \mathrm{PbBr}_{4}$ crystals. The energy resolutions for photo peaks are $10.2 \pm 0.6$ and 7.7 $\pm 0.8 \%$ while those for escape peaks are $9.0 \pm 1.6$ and $8.7 \pm 0.5 \%$ measured in undoped and $\mathrm{Li}$ doped crystals, respectively. 

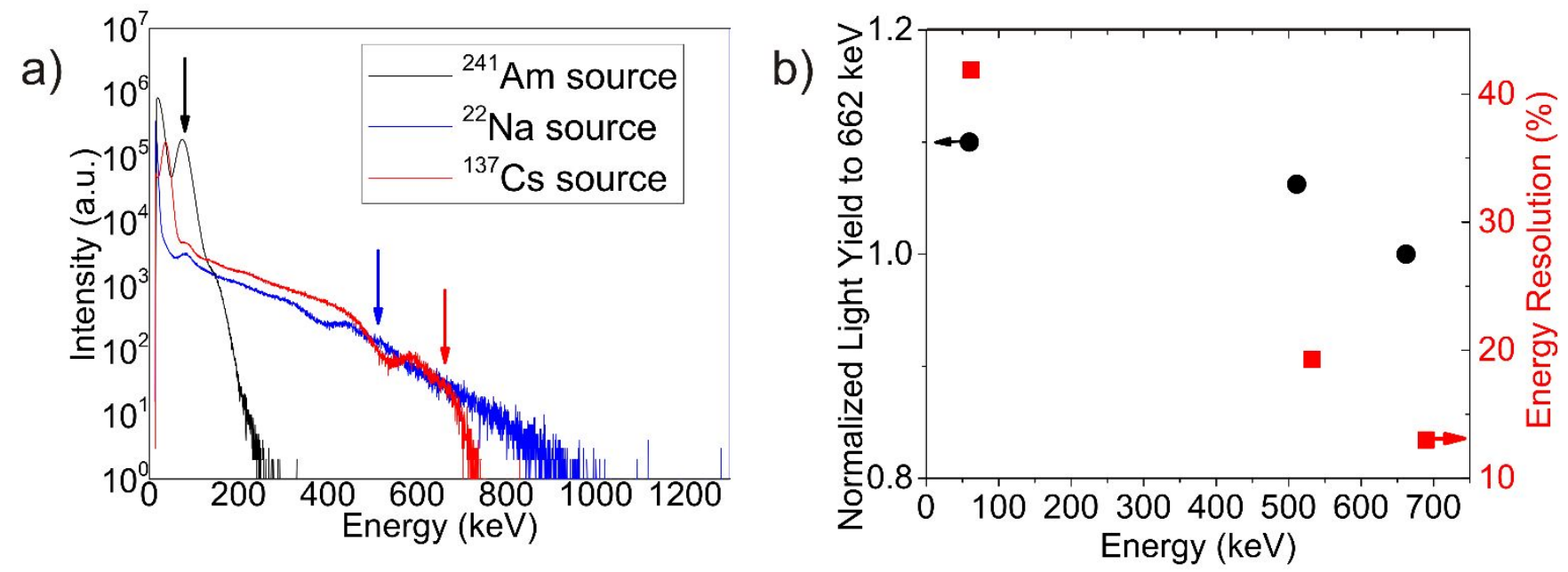

Figure S14. a) Pulse height spectra under gamma-ray excitation with different energies for $(\mathrm{BA})_{2} \mathrm{PbBr}_{4}$. b) The nonproportionality of the light yields and the energy resolutions from pulse height spectra of four crystals. We only estimated the position of the photopeak $72 \mathrm{keV}$ from the escape peak due to the strong overlap between the photopeak and the escape peak. 


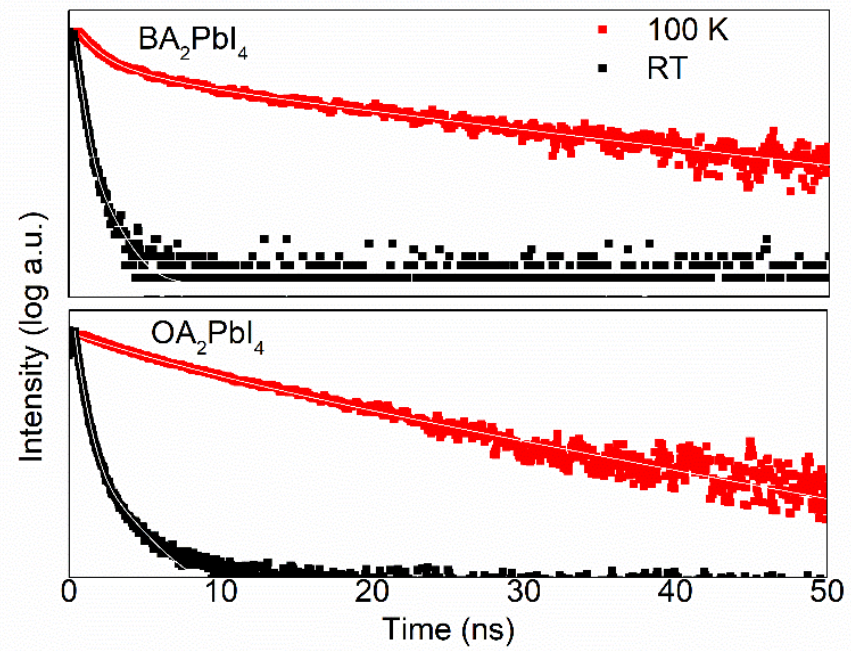

Figure $\mathrm{S} 15$. Time-resolved $\mathrm{PL}$ of single crystals of $(\mathrm{BA})_{2} \mathrm{PbI}_{4}$ and $(\mathrm{OA})_{2} \mathrm{PbI}_{4}$ with excitation at $355 \mathrm{~nm}$ with monitoring emission at $500 \mathrm{~nm}$ at $100 \mathrm{~K}$ and RT. The decay times at $100 \mathrm{~K}$ are slower than those at RT. The temperature dependence measurements were described in Ref. [Arramel2020]. ${ }^{17}$ The respective decay components (and \% contributions) for $(\mathrm{BA})_{2} \mathrm{PbI}_{4}$ and $(\mathrm{OA})_{2} \mathrm{PbI}_{4}$ crystals at RT are listed in Table $\mathrm{S} 2$ while those at $100 \mathrm{~K}$ are $1.0(12 \%), 3.3(14 \%)$, $16.2 \mathrm{~ns}(74 \%)$ and $2.7(13 \%), 8.5(83 \%), 20.1(4 \%)$. The average decay times are 12.5 and 8.2 ns for $(\mathrm{BA})_{2} \mathrm{PbI}_{4}$ and $(\mathrm{OA})_{2} \mathrm{PbI}_{4}$ crystals, respectively. ${ }^{17}$

\section{Reference}

1. Billing, D. G.; Lemmerer, A., Inorganic-organic hybrid materials incorporating primary cyclic ammonium cations: The lead iodide series. CrystEngComm 2007, 9 (3), 236244.

2. Lemmerer, A.; Billing, D. G., Synthesis, characterization and phase transitions of the inorganic-organic layered perovskite-type hybrids [(CnH2n+1NH3)2PbI4], $\mathrm{n}=7,8,9$ and 10 . Dalton Trans. 2012, 41 (4), 1146-1157.

3. Shibuya, K.; Koshimizu, M.; Nishikido, F.; Saito, H.; Kishimoto, S., Poly[bis(phenethylammonium) [dibromidoplumbate(II)]-di-[mu]-bromido]]. Acta Crystallogr. E 2009, 65 (11), m1323-m1324.

4. Smith, M. D.; Jaffe, A.; Dohner, E. R.; Lindenberg, A. M.; Karunadasa, H. I., Structural origins of broadband emission from layered $\mathrm{Pb}-\mathrm{Br}$ hybrid perovskites. Chem. Sci. 2017, 8 (6), 4497-4504.

5. Billing, D. G.; Lemmerer, A., Inorganic-organic hybrid materials incorporating primary cyclic ammonium cations: The lead bromide and chloride series. CrystEngComm 2009, $11(8), 1549-1562$.

6. Billing, D. G.; Lemmerer, A., Synthesis, characterization and phase transitions in the inorganic-organic layered perovskite-type hybrids [(CnH2n $+1 \mathrm{NH} 3) 2 \mathrm{PbI} 4], \mathrm{n}=4,5$ and 6 . Acta Crystallogr. B 2007, 63 (5), 735-747. 
7. Bakthavatsalam, R.; Haris, M. P. U.; Shaikh, S. R.; Lohar, A.; Mohanty, A.; Moghe, D.; Sharma, S.; Biswas, C.; Raavi, S. S. K.; Gonnade, R. G.; Kundu, J., Ligand Structure Directed Dimensionality Reduction $(2 \mathrm{D} \rightarrow 1 \mathrm{D})$ in Lead Bromide Perovskite. J. Phys. Chem. C 2020, 124 (3), 1888-1897.

8. Dohner, E. R.; Jaffe, A.; Bradshaw, L. R.; Karunadasa, H. I., Intrinsic White-Light Emission from Layered Hybrid Perovskites. J. Am. Chem. Soc. 2014, 136 (38), 13154-13157.

9. Li, Y. Y.; Lin, C. K.; Zheng, G. L.; Cheng, Z. Y.; You, H.; Wang, W. D.; Lin, J., Novel $\langle 110\rangle$-Oriented Organic-Inorganic Perovskite Compound Stabilized by N-(3Aminopropyl)imidazole with Improved Optical Properties. Chem. Mater. 2006, 18 (15), 34633469.

10. Han, Y.; Li, Y.; Wang, Y.; Cao, G.; Yue, S.; Zhang, L.; Cui, B.-B.; Chen, Q., From Distortion to Disconnection: Linear Alkyl Diammonium Cations Tune Structure and Photoluminescence of Lead Bromide Perovskites. Adv. Opt. Mater. 2020, 8 (8), 1902051.

11. Ma, D.; Xu, Z.; Wang, F.; Deng, X., Syntheses of two-dimensional propylammonium lead halide perovskite microstructures by a solution route. CrystEngComm 2019, 21 (9), 14581465.

12. Gonzalez-Carrero, S.; Espallargas, G. M.; Galian, R. E.; Pérez-Prieto, J., Blueluminescent organic lead bromide perovskites: highly dispersible and photostable materials. $J$. Mater. Chem. A 2015, 3 (26), 14039-14045.

13. Brylew, K.; Drozdowski, W.; Wojtowicz, A. J.; Kamada, K.; Yoshikawa, A., Studies of low temperature thermoluminescence of GAGG:Ce and LuAG:Pr scintillator crystals using the Tmax-Tstop method. J. Lumin. 2014, 154, 452-457.

14. Dossi, R.; Ianni, A.; Ranucci, G.; Smirnov, O. J., Methods for precise photoelectron counting with photomultipliers. Nucl. Instrum. Meth. in Phys. Res. A 2000, 451 (3), 623-637.

15. De Haas, J. M. T.; Dorenbos, P.; van Eijk, C. W. E. In The absolute light yield of LaBr3: $\mathrm{Ce}$ and $\mathrm{LaCl3}$ : Ce, Proc. Int. Conf. on Inorganic Scintillators and their Applications, Crimea, Ukraine, September 19-23; Crimea, Ukraine, 2005; p 135.

16. Haas, J. T. M. d.; Dorenbos, P., Advances in Yield Calibration of Scintillators. IEEE Trans. Nucl. Sci. 2008, 55 (3), 1086-1092.

17. Arramel; Xie, A.; Yin, X.; Tang, C. S.; Mahyuddin, M. H.; Hettiarachchi, C.; Sahdan, M. F.; Yoshizawa, K.; Dang, C.; Birowosuto, M. D.; Wee, A. T. S.; Rusydi, A., Electronic and Optical Modulation of Metal-Doped Hybrid Organic-Inorganic Perovskites Crystals by PostTreatment Control. ACS Appl. Energy Mater. 2020, 3 (8), 7500-7511. 